\title{
The Configuration of the Femoral Arterial Bifurcation's Influence on Its Atherogenesis
}

\author{
Magaye Gaye ${ }^{1,2 *}$, Papa Adama Dieng², Ainina Ndiaye1, Racky Wade1, Sidy Diop², \\ Ndeye Fatou Sow ${ }^{2}$, Papa Amath Diagne ${ }^{2}$, Souleymane Diatta ${ }^{2}$, Salmane Ba ${ }^{2}$, \\ Mourad Boufi ${ }^{3}$, Assane Ndiaye ${ }^{4}$, Amadou Gabriel Ciss ${ }^{2}$, Abdoulaye Ndiaye ${ }^{1}$ \\ ${ }^{1}$ Laboratory of Anatomy and Organogenesis-FMPO-UCAD, Dakar, Senegal \\ ${ }^{2}$ Thoracic and Cardiovascular Surgery Department-Fann CHNU, Dakar, Senegal \\ ${ }^{3}$ Vascular Surgery Department, North Hospital of Marseille, Marseille, France \\ ${ }^{4}$ Laboratory of Anatomy and Organogenesis-UAS Ziguinchor, Ziguinchor, Senegal \\ Email: *mgaye99@yahoo.fr
}

How to cite this paper: Gaye, M., Dieng, P.A., Ndiaye, A., Wade, R., Diop, S., Sow, N.F., Diagne, P.A., Diatta, S., Ba, S., Boufi, M., Ndiaye, A., Ciss, A.G. and Ndiaye, A. (2020) The Configuration of the Femoral Arterial Bifurcation's Influence on Its Atherogenesis. Forensic Medicine and Anatomy Research, 8, 45-53.

https://doi.org/10.4236/fmar.2020.82005

Received: January 21, 2020

Accepted: April 27, 2020

Published: April 30, 2020

Copyright $\odot 2020$ by author(s) and Scientific Research Publishing Inc. This work is licensed under the Creative Commons Attribution International License (CC BY 4.0).

http://creativecommons.org/licenses/by/4.0/

\begin{abstract}
Several theories point to the influence of the geometry of femoral arterial bifurcation in the formation and evolution of atherosclerosis plaques at the level of common, superficial and deep femoral arteries. The objective of this study is to correlate the degrees of calcifications of the femoral tripod with different morphological parameters, namely conicity, tortuosity, proximal and distal diameters of the arteries and angles between the common femoral artery (CFA) and the superficial femoral artery (SFA) and the profound femoral artery (PFA) and the superficial femoral artery. The results showed that only the tortuosity of the common femoral artery influences the formation of atherosclerosis plaque. These results allow us to predict the degree of calcification of the femoral tripod based on the tortuosity of the common femoral artery.
\end{abstract}

\section{Keywords}

Tortuosity, Calcification, Atherosclerosis, Femoral Arterial Bifurcation

\section{Introduction}

Arterial calcifications are clearly related to mortality. The Kaplan-Meier 5-year survival curve is less than $50 \%$ in patients with chronic renal failure with atherosclerotic calcification or medial calcification and $90 \%$ in patients without arterial calcification [1]. After adjustment for age, dialysis, gender, ethnicity, diabetes, non-dialysis renal failure, hypertension, smoking, parathyroid surgery, body mass index, medial and intimal calcification increase the relative risk of mortality by 5 and 12 times compared to patients without calcification [2]. 
Calcifications alter the morphology and compliance of the arterial wall and thus reduce the effectiveness of angioplasty and stenting [3]. Technical success and permeability are altered in cases of severe arterial calcifications [4] by increasing the risk of arterial dissection and recoil [3] after balloon angioplasty and by promoting under-expansion, malposition and fracture of stents [5] [6]. The femoral tripod is known to have specific calcifications constitutionally, but also in relation to their resistance to stenting angioplasty [7]. Indeed, among the theories of atherogenesis, morphology is often present [8] [9] [10] [11]. Consequently, the aim of this work is to evaluate the influence of a few morphological parameters on atherogenesis.

\section{Material and Method}

This is a retrospective study from January 2015 to July 2017 involving 65 patients (70 sides) who were hospitalized in the Vascular Surgery Department of the North Hospital of Marseille for the surgical management of lower limb arteriopathy related to femoral tripod lesions.

The inclusion criteria concern patients with 1) significant femoral tripod lesions isolated or associated with other lesions, 2) treated by conventional surgery isolated or associated with an endovascular gesture of the upstream or downstream lesions, and 3) having an angioTDM imaging.

Exclusion criteria are the absence of good quality lower limb artery CT angio angiography to allow extraction of a central line.

From the angioCTM, using the EndoSize image processing software, images are transferred in DICOM format to a console with this software. After the determination of a proximal point at the birth of the common femoral artery (CFA) using the birth of the epigastric artery as a reference point, and a distal point located $5 \mathrm{~cm}$ downstream of the birth of the superficial femoral artery (AFS) an automatic segmentation is performed followed by the extraction of a 3D primary central line. A second secondary central line is then created starting at the femoral bifurcation and ending $5 \mathrm{~cm}$ downstream from the birth of the deep femoral artery (DFA).

The morphological parameters analyzed are:

- The length of the common femoral artery.

- The proximal and distal diameters of the common, superficial and deep femoral arteries.

- The angle $\alpha$ formed between the common femoral artery and the deep femoral artery and the angle $\theta$ between the superficial femoral artery and the deep femoral artery. The measurements were made on $3 \mathrm{D}$ images using a $90^{\circ}$ right anterior oblique incidence as a reference (Figure 1).

- The conicity between the common femoral artery and the deep and superficial femoral arteries. Conicity is the ratio of proximal diameters between the CFA and the AFS or AFP. This conicity is evaluated according to Albertini et al. [12] (Figure 1) which defines a coefficient $\alpha$ calculated from the prox imal 
diameter of the artery $(D 1)$, the distal diameter $(D 2)$, the diameter in the middle of the artery $(D 3)$ and the length of the artery $(L)$. Thus:

$$
\alpha=\operatorname{arctangent}((D 3-D 1) / L) \times 180 / \pi
$$

The conical (conical) or inverted conical shape is determined if the absolute value of the coefficient $\alpha$ is greater than or equal to 10 . If the coefficient is less than 10 , the shape is called straight.

Two other shapes do not depend on the coefficient. These are the hourglass shape which is determined if $D 1>D 2$ and $D 3>D 2$ and the barrel shape if $D 1<$ $D 2$ and $D 3<D 2$ (Figure 2).

- The tortuosity of the femoral arteries is common, superficial and deep. The latter is the ratio between the vertical length of the artery and its actual length.

- The evaluation of the degree of calcification of the femoral tripod is made according to the calcium score of the peripheral arterial research consortium (PARC). It is based on the circumference of the calcifications on the artery and their lengths. By combining these two criteria: length, less than half the length of the lesion or more than half, and circumference, $<180^{\circ}$ or $>180^{\circ}$, calcium lesions are classified into 5 grades: Absent, focal, mild, moderate and severe (Table 1).

- Univariate and multivariate analyses were performed to determine atheromatous calcification and the following femoral tripod morphological parameters: tortuosity, conicity, and AFC-AFP and AFS-AFP angles. The tests used were the Mann-Whitney $\mathrm{U}$ and the Wilcoxon W.

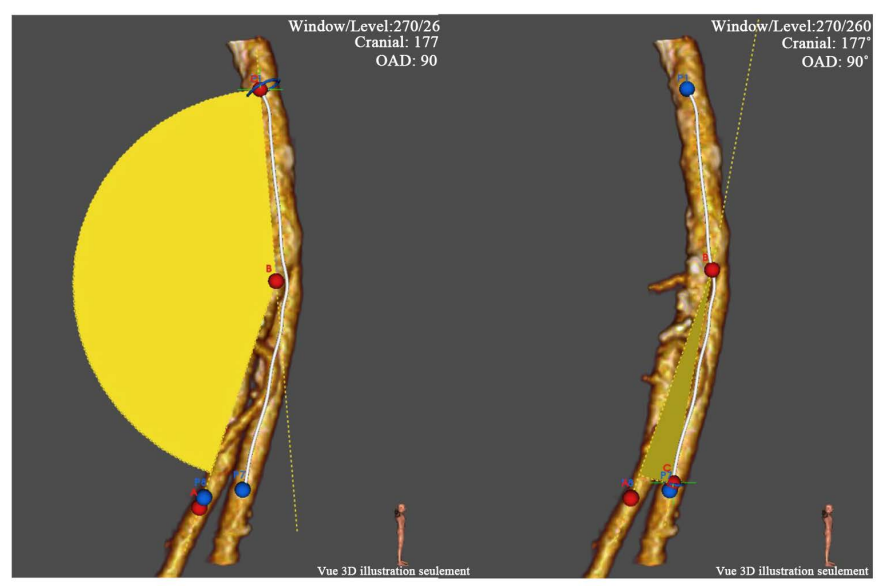

Figure 1. Methods of measuring angles CFA/PFA and CFA/SFA.

Table 1. PARC calcium score evaluation [3].

\begin{tabular}{|c|c|c|c|c|}
\hline Absence & Focale & Légère & Modérée & Sévère \\
\hline No & $\begin{array}{l}<180^{\circ} \text { on one } \\
\text { side of the vessel }\end{array}$ & $\begin{array}{l}<180^{\circ} \text { on one } \\
\text { side of the vessel }\end{array}$ & $\begin{array}{l}>180^{\circ} \text { of the } \\
\text { two sides } \\
\text { of the vessel }\end{array}$ & $\begin{array}{l}>180^{\circ} \text { of the } \\
\text { two sides } \\
\text { of the vessel }\end{array}$ \\
\hline calcification & $\begin{array}{c}\text { Less than the half } \\
\text { of the length } \\
\text { of the vessel }\end{array}$ & $\begin{array}{c}\text { Upper than the } \\
\text { half of the length } \\
\text { of the vessel }\end{array}$ & $\begin{array}{c}\text { Less than the half } \\
\text { of the length } \\
\text { of the vessel }\end{array}$ & $\begin{array}{l}\text { Upper than the } \\
\text { half of the length } \\
\text { of the vessel }\end{array}$ \\
\hline
\end{tabular}



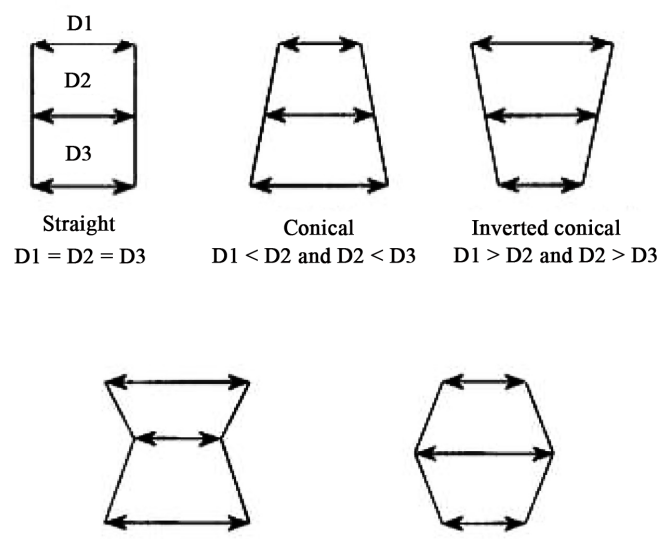

Hourglass

Barrel

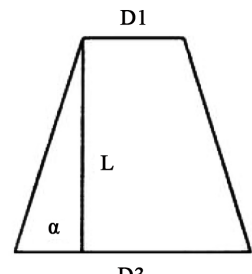

$\alpha=$ arctangent $((\mathrm{D} 3-\mathrm{D} 1) / \mathrm{L}) \times 180 / \pi$

Figure 2. Conicity assessment method [12].

\section{Results}

\section{- Length and diameters}

The average length of the AFC was $45.5 \mathrm{~mm}$. The mean proximal diameter of the AFC was $8.2 \mathrm{~mm}$, the mean diameter of the AFS was $6.7 \mathrm{~mm}$, and the mean diameter of the AFP was $6.3 \mathrm{~mm}$. The mean distal diameter of the CFA was 9.3 $\mathrm{mm}$, the mean distal diameter of the AFS was $6.2 \mathrm{~mm}$, and the mean distal diameter of the AFP was $5.2 \mathrm{~mm}$ (Table 2).

\section{- Angles AFC/AFP and AFS/AFP}

The angle formed by the AFC and the AFP, on a $90^{\circ} \mathrm{ADO}$ incidence, averaged $157^{\circ}$ and that between the AFC and the AFS was $23.8^{\circ}$ (Table 2).

\section{- Conicity assessment AFC, AFC-AFS and AFC-AFP}

The conical shape was found in $1 \%$ of cases for the AFC, in $84 \%$ of cases for the AFC-AFS couple and in 3\% for the AFC-AFP couple. The inverted conical shape was found in $12 \%$ of cases in the AFC-AFS couple and $78 \%$ in the AFC-AFP couple. On the other hand, this configuration was not found in the AFC. On the other hand, the straight configuration was present in $99 \%$ of cases in the AFC, in $84 \%$ of cases in the AFC-AFS and in 3\% of cases in the AFC-AFP (Figure 3).

- Tortuosity assessment AFC, AFC-AFS and AFC-AFP

The tortuous configuration was found in half of the cases in the AFC, in $48 \%$ of the cases in the AFC-AFP couple and in $83 \%$ of the cases in the AFC-AFP couple (Figure 4). 


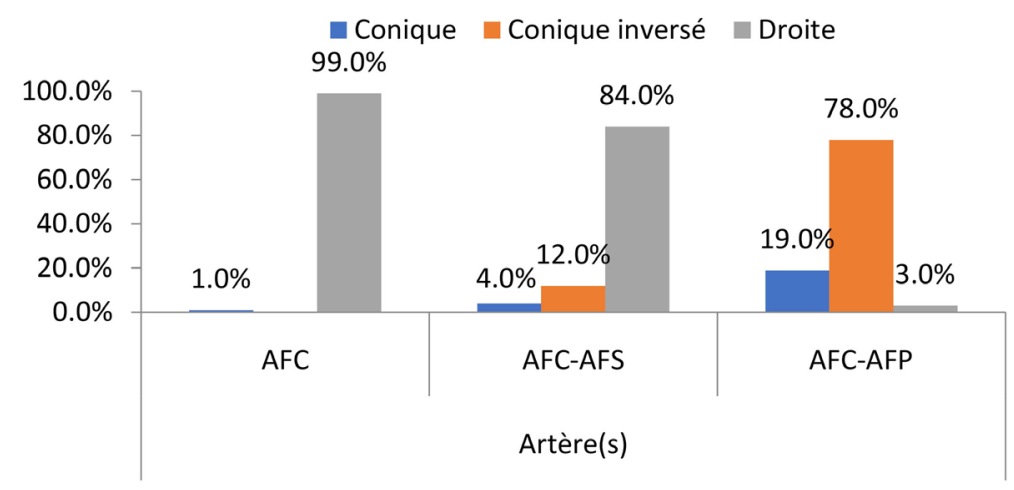

Figure 3. Conicity distribution.

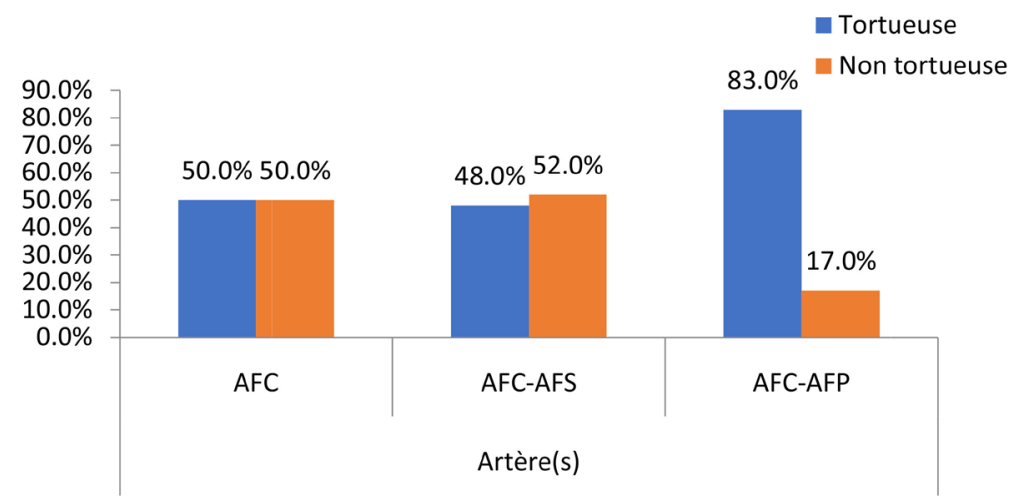

Figure 4. Distribution of tortuosity at the femoral tripod.

Table 2. Morphological parameters.

\begin{tabular}{ccc}
\hline Paramètres & Moyenne & Extrêmes \\
\hline CFA length $(\mathrm{mm})$ & 45.5 & $16-74$ \\
CFA proximal diameter $(\mathrm{mm})$ & 8.2 & $4.3-15.3$ \\
CFA distal diameter $(\mathrm{mm})$ & 9.3 & $4.5-16.3$ \\
SFA proximal diameter $(\mathrm{mm})$ & 6.7 & $0.3-12.3$ \\
SFA distal diameter $(\mathrm{mm})$ & 6.2 & $2.4-12.2$ \\
PFA proximal diameter $(\mathrm{mm})$ & 6.2 & $3.2-10.3$ \\
PFA distal diameter $(\mathrm{mm})$ & 5.2 & $2-9.4$ \\
CFA/PFA angle (degree) & 157 & $140.2-171.4$ \\
SFA/PFA angle (degree) & 23.3 & $13.3-64$
\end{tabular}

\section{- The PARC calcification assessment}

Seventy-five (7\%) of patients had a high femoral tripod calcium score (PARC) (Figures 5-8).

\section{- Correlations and comparisons}

According to the Mann-Witney $\mathrm{U}$ and Wilcoxon W tests, only the tortuosity of the common femoral artery is correlated with calcification of the femoral tripod (Table 3 ). 


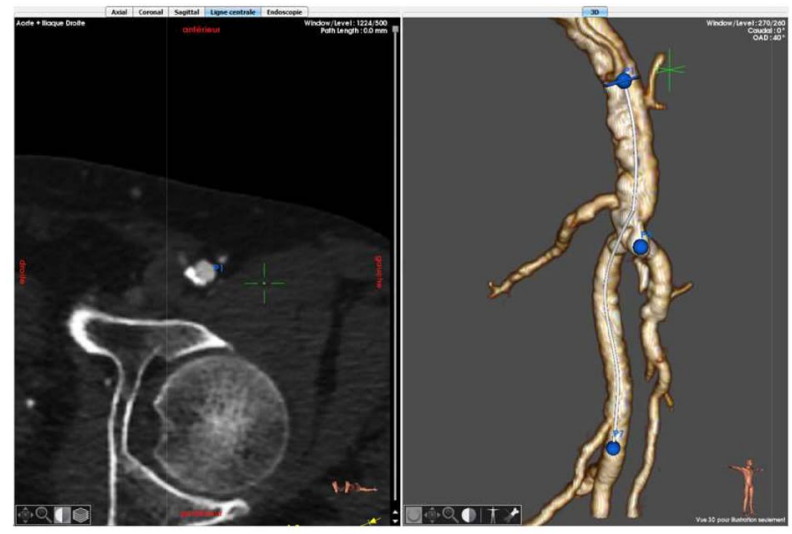

Blue points: center lineslandmark

Figure 5. PARC calcium score 1: 10\% $(\mathrm{n}=7)$.

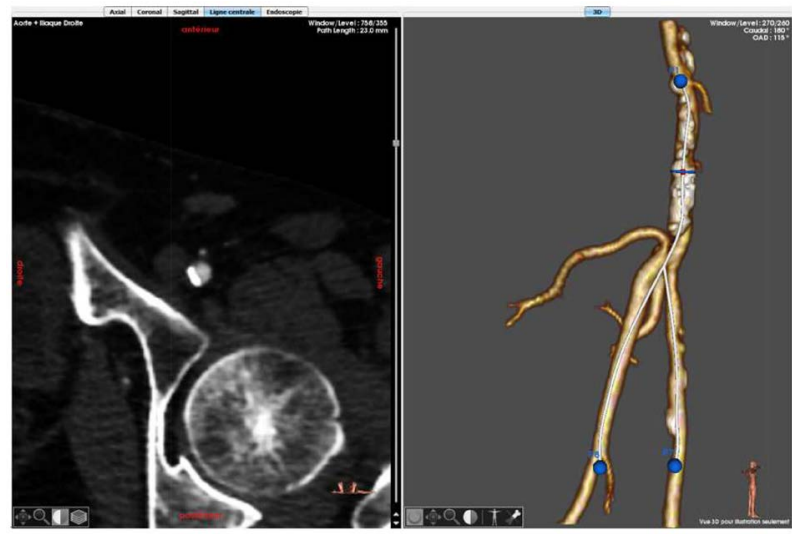

Blue points: center lineslandmark

Figure 6. PARC calcium score 2: $14.3 \%(\mathrm{n}=10)$.

Table 3. Correlations and comparisons of calcification degree and morphological parameters.

\begin{tabular}{ccccc}
\hline & Mann-Whitney & Wilcoxon & Z & $\begin{array}{c}\text { Asymp. Sig. } \\
(2 \text {-tailed })\end{array}$ \\
& U & W & & 0.606 \\
AFC LENGHT $(\mathrm{mm})$ & 405,000 & 1783,000 & -0.516 & 0.112 \\
PROX AFC DIAMETER $(\mathrm{mm})$ & 334,500 & 487,500 & -1589 & 0.236 \\
DIST AFC DIAMETER $(\mathrm{mm})$ & 364,000 & 517,000 & -1.185 & 0.609 \\
PROX SFA DIAMETER $(\mathrm{mm})$ & 389,500 & 542,500 & -0.512 & 0.692 \\
DIST SFA DIAMETER $(\mathrm{mm})$ & 289,500 & 380,500 & -0.396 & 0.749 \\
PROX FPA DIAMETER $(\mathrm{mm})$ & 419,000 & 572,000 & -0.320 & 0.615 \\
DIST FPA DIAMETER $(\mathrm{mm})$ & 398,000 & 551,000 & -0.503 & 0.128 \\
CFA/FPA ANGLE (degree) & 339,500 & 492,500 & -1520 & 0.768 \\
SFA/PFA ANGLE (degree) & 429,000 & 1860,000 & -0.295 & 0.031 \\
CFA TORTUOSITY INDEX & 295,000 & 448,000 & -2158 & 0.128 \\
CFA-AFS TORTUOSITY INDEX & 340,500 & 493,500 & -1523 & 0.736 \\
\hline CFA-FPA TORTUOSITY INDEX & 426,000 & 579,000 & -0.336 & \\
\hline
\end{tabular}




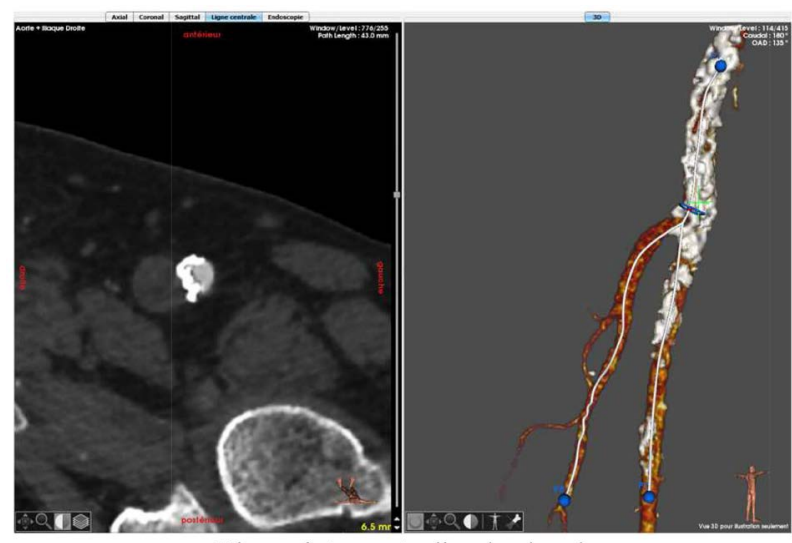

Blue points: center lineslandmark

Figure 7. PARC calcium score 3: $18.16 \%(\mathrm{n}=13)$.

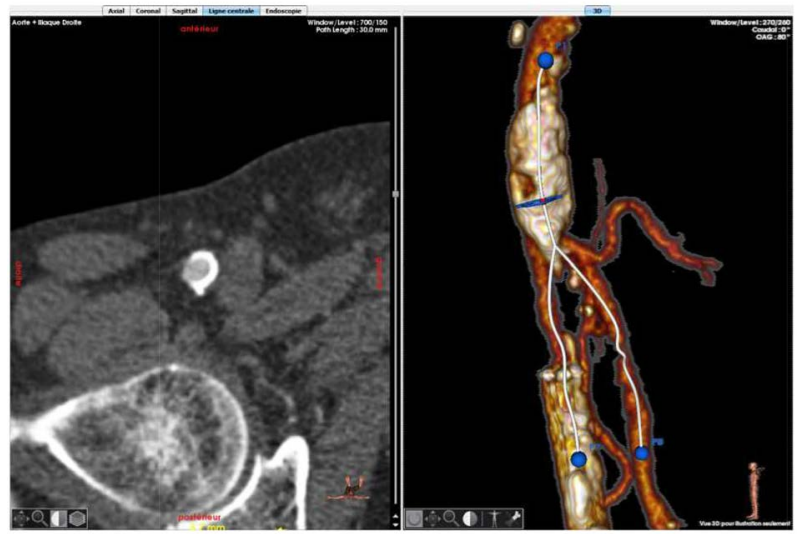

Blue points: center lineslandmark

Figure 8. PARC calcium score 4: 57.1\% $(\mathrm{n}=40)$.

\section{Discussion}

The geometry of the artery influences the formation and deposition of atheromatous plaques. Takayuki [13], in an experimental study in rabbits, described the distribution of atheromatous plaques around arterial bifurcations. A comparative study on the symmetry between the carotid artery and the femoral bifurcation, concerning the deposition of atheromatous plaques, shows perfect symmetry at the carotid level. On the other hand, at the femoral bifurcation, asymmetry of atheromatous plaques is observed [9]. These clinical facts can be explained by the almost rectilinear path of the carotid artery, whereas the common femoral artery and its branches show a tortuous path [9]. Indeed, our work shows, through a statistical correlation, that the tortuosity of the common femoral artery has an influence on its atheromatous calcification. This discovery is all the more important since all morphological studies of the femoral tripod in relation to atherogenesis only concern the superficial femoral artery. Wood [10] states that curvature and tortuosity of the femoral artery constitute real risks of atherosclerosis. Smedy [11] states that curvatures with a medial concavity are more at risk than those with a lateral concavity and straight artery segments. In addition, the su- 
perior femoral artery as well as the common and deep femoral arteries are mobile with hip and knee movements [14]. Therefore, hemodynamically, the flow shear forces in the superficial femoral artery are more pronounced when changing position (from supine to sitting position) compared to the supine position [15]. Indeed, we can affirm that at the level of the common femoral artery, the tortuosity associated with mobility during hip movement constitute risk factors for the formation and deposition of atheromatous plaques.

\section{Conclusion}

The tortuosity of the common femoral artery certainly has an influence on the atherogenesis of the femoral tripod, but this work should make us reflect on the technical failures and poor short-term results of endovascular surgery of the femoral tripod. Indeed, tortuosity is a calcification factor which itself aggravates tortuosity. A biomechanical simulation should allow us to understand the mechanisms of this clinical-radiological fact.

\section{Authorization of the Ethics Committee}

The Ethics Committee of our Faculty of Medicine gave us its agreement for the realization of this study.

The patients on which were realized various measures gave their consent for the publication.

\section{Conflicts of Interest}

The authors declare no conflicts of interest regarding the publication of this paper.

\section{References}

[1] Bithika, T. and Dwight, A.T. (2012) Arterial Calcification and Bone Physiology: Role of the Bone-Vascular Axis. Nature Reviews Endocrinology, 8, 529-543. https://doi.org/10.1038/nrendo.2012.36

[2] Lehto, L.J., Sierra, A., Corum, C.A., et al. (2012) Detection of Calcifications in Vivo and ex Vivo after Brain Injury in Rat Using SWIFT. NeuroImage, 61, 761-772. https://doi.org/10.1016/j.neuroimage.2012.03.002

[3] Fanelli, F., Cannavale, A., Gazzetti, M., et al. (2014) Calcium Burden Assessment and Impact on Drug-Eluting Balloons in Peripheral Arterial Disease. CardioVascular and Interventional Radiology, 37, 898-907. https://doi.org/10.1007/s00270-014-0904-3

[4] Schillinger, M. and Minar, E. (2012) Percutaneous Treatment of Peripheral Artery Disease: Novel Techniques. Circulation, 126, 2433-2440. https://doi.org/10.1161/CIRCULATIONAHA.111.036574

[5] Halwani, D.O., Anderson, P.G., Brott, B.C., et al. (2011) The Role if Vascular Calcification in Inducing Fatigue and Fracture of Coronary Stents. Journal of Biomedical Materials Research Part B: Applied Biomaterials, 100, 292-304. https://doi.org/10.1002/jbm.b.31911

[6] Cioppa, A., Stabile, E., Popusoi, G., et al. (2012) Combined Treatment of Heavy 
Calcified Femoro-Popliteal Lesions Using Directional Athertectomy and a Paclitaxel Coated Balloon: One Year Single Center Clinical Results. Cardiovascular Revascularization Medicine, 13, 219-223. https://doi.org/10.1016/j.carrev.2012.04.007

[7] Lanzer, P., Boehm, M., Sorribas, V., et al. (2014) Medial Vascular Calcification Revisited: Review and Perspectives. European Heart Journal, 35, 1515-1525. https://doi.org/10.1093/eurheartj/ehu163

[8] Tegos, T.J., Kalodiki, E., Sabetai, M.M., et al. (2001) The Genesis of Atheosclerosis and Risk Factors: A Review. Angiology, 52, 89-98. https://doi.org/10.1177/000331970105200201

[9] Bossuyt, J., Van Bortel, L.M., De Backer, T.L.M., et al. (2014) Asymmetry in Prevalence of Femoral but not Carotid Atherosclerosis. Journal of Hypertension, 32, 1429-1434. https://doi.org/10.1097/HJH.0000000000000205

[10] Wood, N.B., Zhao, S.Z., Zambanini, A., et al. (2006) Curvature and Tortuosity of the Superficial Femoral Artery: A Possible Risk Factor for Peripheral Arterial Disease. Journal of Applied Physiology, 101, 1412-1418. https://doi.org/10.1152/japplphysiol.00051.2006

[11] Smedby, R. (1998) Geometrical Risk Factors for Atherosclerosis in the Femoral Artery: A Longitudinal Angiographic Study. Annals of Biomedical Engineering, 26, 391-397. https://doi.org/10.1114/1.121

[12] Albertini J.N., Kalliafas S. and Travis, S. (2000) Anatomical Risk Factors for Proximal Perigraft Endoleak and Graft Migration Following Endovascular Repair of Abdominal Aortic Aneurysms. European Journal of Vascular and Endovascular Surgery, 19, 308-312. https://doi.org/10.1053/ejvs.1999.1045

[13] Takayuki, N., Akio, K., Norie, K. and Masashi, S. (2019) Distribution of Atherosclerotic Lesions in Various Arteries of WHHLMI Rabbits, an Animal Model of Familial Hypercholesterolemia. Experimental Animals, 68, 293-300. https://doi.org/10.1538/expanim.18-0175

[14] Lopez, J.F., Magne, J.L. and Champetier, J. (1989) The Femoral Artery and Flexion of the Hip Joint. Surgical and Radiologic Anatomy, 11, 275-281. https://doi.org/10.1007/BF02098696

[15] Schlager, O., Giurgea, A., Margeta, C., et al. (2011) Wall Shear Stress in the Superficial Femoral Artery of Healthy Adults and Its Response to Postural Changes and Exercise. European Journal of Vascular and Endovascular Surgery, 41, 821-827. https://doi.org/10.1016/j.ejvs.2011.01.006 